\title{
Health Care Utilization and Direct Costs Among Patients Diagnosed with Cluster Headache in U.S. Health Care Claims Data
}

\author{
Casey K. Choong, MPH; Janet H. Ford, PhD; Allen W. Nyhuis, MS; Rebecca L. Robinson, MS; \\ and Sheena K. Aurora, MD
}

\begin{abstract}
BACKGROUND: Cluster headache $(\mathrm{CH})$ is a rare trigeminal cephalalgia that is associated with extremely painful unilateral headache attacks and autonomic symptoms. Attacks may be episodic or chronic and associated with substantial suffering due to excruciating pain and limited treatment options. Frequent cluster headaches cause substantial burden for patients, resulting in reduced productivity caused by disability, as well as direct costs in some European countries. Less is known, however, about direct costs of recurring health care resource utilization (HCRU) in the United States.
\end{abstract}

OBJECTIVE: To characterize HCRU and direct costs associated with $\mathrm{CH}$ in the United States from a third-party payer perspective.

METHODS: This retrospective observational study analyzed claims data from the Truven Health Analytics MarketScan Research Databases from 2009-2014. Two cohorts were compared: $\mathrm{CH}$ (>2 diagnostic $\mathrm{CH}$ claims) and controls (nonheadache patients). All patients were enrolled continuously for \pm 12 months from date of first CH claim. HCRU and direct costs were examined during 12 months post-index as all-cause and $\mathrm{CH}$-specific. Cost and HCRU differences were compared using propensity score-adjusted bin bootstrapping.

RESULTS: CH and control cohorts comprised 6,562 and 143,761 patients (aged $\geq 18$ years), respectively. Post-index, $36.9 \%$ of $\mathrm{CH}$ patients versus $16.2 \%$ of controls were admitted to the emergency department (ED), and $14.8 \%$ versus $6.1 \%$ were hospitalized for any reason, respectively (each $P<0.001)$. CH patients had a 2- to 3 -fold significantly greater number of all-cause mean claims for outpatient visits ( 26.5 vs. 12.4 visits), hospital visits ( 0.2 vs. 0.1 visits), and ED visits ( 1.0 vs. 0.3 visits) versus controls (all $P<0.001$ ). The mean number of all-cause visits with reported radiology and laboratory claims was 1.5 - to 2.0 -fold greater in $\mathrm{CH}$ patients versus controls (each $P<0.001$ ). Mean total direct costs for all-cause claims were more than 2-fold greater in post-index $(\$ 16,530)$ for $\mathrm{CH}$ patients versus controls $(\$ 7,197, P<0.0001)$. Similarly, mean direct all-cause costs attributable to outpatient, inpatient, and pharmacy claims were significantly (2-fold) greater; radiology and ED claims were 3- to 4-fold greater among $\mathrm{CH}$ patients versus controls (all $P<0.001$ ). However, $\mathrm{CH}$ was cited infrequently as a reason for HCRU, indicating that comorbid conditions may substantially increase $\mathrm{HCRU}$ in $\mathrm{CH}$ patients. The most common reasons for ED admission in $\mathrm{CH}$ patients were gastric ulcer with hemorrhage, subarachnoid hemorrhage, and headache symptoms. The most common hospital discharge diagnoses for $\mathrm{CH}$ patients not observed in top 10 reasons in controls included cerebral artery occlusion/unspecified with cerebral infarction, headache symptoms, syncope/collapse, and diverticulitis.

CONCLUSIONS: These findings suggest that, from a payer perspective, $\mathrm{CH}$ patients incur significantly higher health care costs versus controls. However, these high costs were not exclusively headache-related. Extrapolating our cost findings to estimated U.S. prevalence rates, approximate total direct cost for $\mathrm{CH}$ is greater than $\$ 2.8$ billion/year.

J Manag Care Spec Pharm. 2018;24(9):921-28

Copyright $\odot 2018$, Academy of Managed Care Pharmacy. All rights reserved.

\section{What is already known about this subject}

Cluster headache patients suffer from extreme physical and emotional distress, and the disease significantly affects their work productivity and quality of life.

Several European studies have addressed health care costs attributable to the disease and found that patients with chronic and active episodic cluster headache were severely impaired in noneconomic and economic (indirect and direct costs) domains such as disability, loss of working capacity, and psychiatric complaints that have considerable effect on social functions, quality of life, and health care utilization.

\section{What this study adds}

This is the first study to document direct health care costs and resource utilization among patients with a cluster headache diagnosis in the United States, compared with controls.

Cluster headache patients used significantly more health care resources compared with controls; comorbid conditions among cluster headache patients may be the cost driver.

Reasons for emergency department visits and hospital admissions in cluster headache patients were not limited to headache- or migraine-related claims.

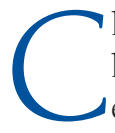
luster headache $(\mathrm{CH})$, often referred to as "suicide headache," is well characterized by excruciating unilateral pain (orbital, supraorbital, and/or temporal) with attacks occurring daily to multiple times per day for weeks or months followed by periods of remission. ${ }^{1}$ Its pathogenesis is complex with evidence suggesting that the trigeminovascular system and neurogenic inflammation play important roles and that activation of the hypothalamus appears to be a key factor in generating attacks. ${ }^{2}$ The epidemiology of $\mathrm{CH}$ is scant due to its rarity (estimated lifetime prevalence of 124 per 100,000$)^{3}$ and shows a 3-fold male preponderance. ${ }^{1}$ Recognition of $\mathrm{CH}$ in the United States has increased since 2008 with introduction of diagnostic codes and published evidence-based treatment recommendations of the American Headache Society. ${ }^{4,5}$ However, a greater understanding of treatment practices and economics is needed.

Frequent $\mathrm{CH}$ episodes trigger substantial financial burden beyond the medical care for headache. Three studies com- 
pleted in the European Union provide evidence that $\mathrm{CH}$ is associated with sizeable indirect costs (high number of days lost from work, reduced activities, early retirement). ${ }^{6-8}$ In 1 study, patients were absent from work an average of 8.5 days per 6 months due to $\mathrm{CH}$-specific illness. ${ }^{7}$ Approximately 25\% of $\mathrm{CH}$ patients reported a major decrease in their ability to participate in social activities, family life, and housework, ${ }^{8}$ and severe disability was reported by $13 \%$ to $25 \%$ of patients. ${ }^{6,7}$ Although economic data are limited for $\mathrm{CH}$, medications in the European Union studies were responsible for $89.7 \%$ of direct costs, with oxygen being a key treatment. ${ }^{7}$ These findings contrast with U.S. treatment patterns, where oxygen is less likely to be used. ${ }^{9}$ Furthermore, we recently reported that the burden of $\mathrm{CH}$ is associated with significant comorbidity (e.g., depression, anxiety), higher rates of substance abuse (3-fold) and suicidal ideation (2.5-fold) compared with nonheadache controls, and treatment patterns indicating low use of recognized $\mathrm{CH}$ treatments $(\sim 30 \%))^{10}$

Published U.S.-based cost and burden data for $\mathrm{CH}$ patients are limited. Therefore, the specific aim of this study was to identify health care resource utilization (HCRU) and health care costs using the Truven Health Analytics MarketScan Research Databases and to compare findings in $\mathrm{CH}$ patients with those of a control group. We hypothesized that $\mathrm{CH}$ patients would have significantly higher rates of HCRU and total direct health care costs versus controls.

\section{Methods}

\section{Study Design and Data Sources}

Claims data from the Truven Health Analytics Marketscan Research Databases from January 1, 2009, through December 31, 2014, were extracted and analyzed for this observational, retrospective database study. Beneficiaries included employees and their covered dependents insured through large U.S. employers and health plans as well as individuals with supplemental Medicare coverage. Medicaid was excluded in this analysis due to very different provider payment levels and because Medicaid enrollees have far greater health care needs and greater prevalence of disability versus low-income privately insured populations; these factors might skew HCRU results. ${ }^{11}$ The database includes de-identified administrative claims capturing patient-level data on age, gender, geographic region, HCRU, expenditures, and enrollment across inpatient, outpatient, prescription drug, and carve-out services. This data source links paid claims data, capturing when services occurred, and diagnosis codes via the International Classification of Diseases, Ninth Revision, Clinical Modification (ICD-9-CM), Healthcare Common Procedure Coding System, and Current Procedural Terminology codes. Institutional review board approval was not required due to the de-identified nature of this existing data source and methods to protect both patients and health care sites.

\section{Patient Selection}

Two patient cohorts were identified: $\mathrm{CH}$ and control. The $\mathrm{CH}$ cohort included patients with $\geq 2$ medical diagnoses for $\mathrm{CH}$ (ICD-9-CM medical codes including $\mathrm{CH}$ unspecified 339.00, episodic CH 339.01, or chronic CH 339.02) between January 1, 2010, and December 31, 2013, with continuous enrollment 12 months before (pre-index) and after (post-index) the index date, allowing for a single gap of 45 days or fewer between re-enrollment during the 12 months pre-index and 12 months post-index. The index event date was equal to the date of the first $\mathrm{CH}$ diagnosis. The second $\mathrm{CH}$ diagnosis was required to be within 1 year of the index event. Patients with $\mathrm{CH}$ during the pre-index were excluded. Approximately 20 control patients were randomly selected for each $\mathrm{CH}$ patient. This control cohort included patients who had no claim for $\mathrm{CH}$ using ICD-9-CM codes above or any other headache diagnosis (339.xx, 346.xx, and 377.xx) between January 1, 2009, and December 31, 2014. However, the ICD-9-CM code 784.0 (headache symptoms) was not excluded. The index date for control patients was the closest date to that of matched $\mathrm{CH}$ patients (i.e., within the same index year as $\mathrm{CH}$ patients). Patients in both cohorts were aged $\geq 18$ years at the index date with 24 months of continuous enrollment, allowing for a single gap of 45 days or less between re-enrollment.

\section{Outcome Measures: HCRU and Direct Costs}

HCRU and direct costs were quantified from the claims database during the pre-index and post-index including costs of paid claims associated with all-cause (any reason), headache-related, and $\mathrm{CH}$-specific claims. Headacherelated events were defined with ICD-9-CM codes 339.xx other headache syndrome, 784.0 headache symptoms, 307.81 tension headache, and 346.xx migraine. $\mathrm{CH}$-specific events were defined with ICD-9-CM codes 339.00, 339.01, and 339.02. Costs were reported as the total gross payment from the payer perspective for a specific service (i.e., amount eligible for payment after applying pricing guidelines such as fee schedules and discounts, and before applying deductibles, co-payments, and coordination of benefits and other savings). The proportion of patients with any visit/utilization and mean number of visits (i.e., unique date of visit, wherein multiple visits on the same day were counted as 1 visit) for any outpatient, inpatient hospitalization, emergency department (ED), laboratory, neurology, radiology services, and outpatient pharmacy (proportion with claim only) service were collected for $\mathrm{CH}$ patients and controls. Radiology services and neurology visits could occur in any setting (e.g., inpatient or outpatient) and were not mutually exclusive with other categories. The top 10 reasons for inpatient hospital admissions or ED visits for $\mathrm{CH}$ patients versus controls were tabulated; ranking and percentage of each reason relative to controls were also calculated. 


\section{FIGURE 1 Patient Selection and Flow}

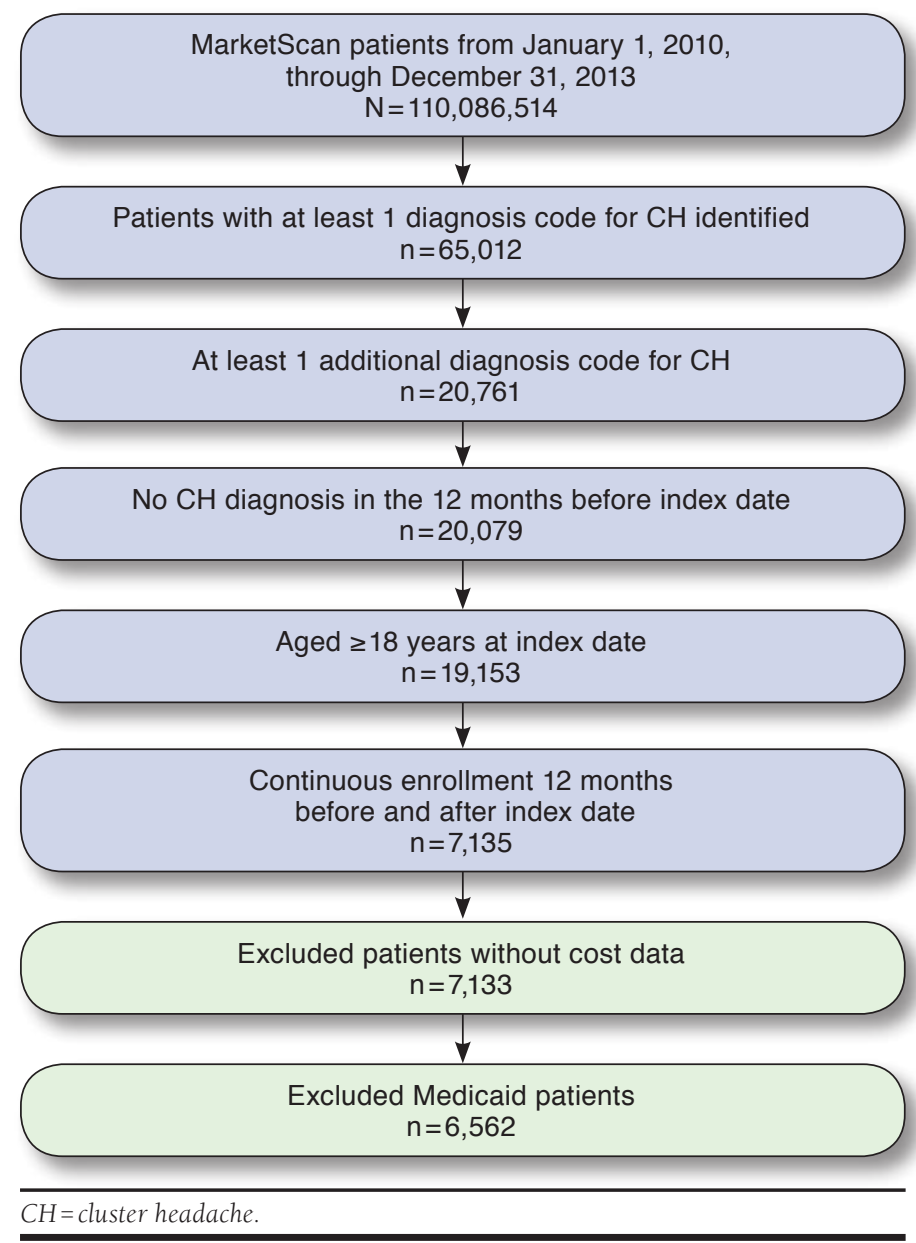

Direct health care costs (for each patient in both cohorts) were calculated as an overall total cost and for each cost element (i.e., outpatient, inpatient hospitalization, ED, and outpatient pharmacy services). Costs were adjusted for inflation using the 2014 medical care services of the Consumer Price Index. For each care setting (i.e., outpatient, inpatient, and ED), the mean number of visits and cost of laboratory, neurology, and radiology claims were calculated.

\section{Statistical Analysis}

Standard summary descriptive statistics were presented for $\mathrm{CH}$ patients and controls. Continuous variables were summarized with number of patients, mean, standard deviation, median, and range statistics. Unadjusted HCRU and direct costs were reported throughout; however, $P$ values (and 95\% confidence intervals [CIs] for the difference) for group comparisons were adjusted using the propensity score-adjusted bin bootstrapping (PSBB) method. Categorical variables were summarized as frequency and percentage of patients in each category. For all statistical comparisons, a 2-sided 5\% significance level was used.

Because cost and HCRU data tend to have a skewed distribution, a PSBB method was used to compare cost and HCRU differences between $\mathrm{CH}$ patients and controls to minimize potential biases between the cohorts. ${ }^{12}$ PSBB involved the following 4 steps: (1) The propensity score (PS) for each patient was computed using logistic regression with presence in the $\mathrm{CH}$ group as the binary dependent variable; (2) all patients were grouped into 10 strata of equal size based on PS deciles; (3) within each of these 10 decile strata, 1,000 bootstrap random resamples (5,000 for total cost) were drawn for each of the $\mathrm{CH}$ and control groups; and (4) the difference in means between the $\mathrm{CH}$ and control groups was computed for each of 1,000 replications. Means, standard deviations, CIs, and $P$ values were computed from the 1,000 bootstrap resamples. The variables used in the PSBB adjustment (for computing the PS) included age, gender, insurance type, Charlson Comorbidity Index,$^{13}$ total net cost in pre-index, geographic region, and 2-way interactions between the above variables. All analyses were performed using SAS version 9.2 (SAS Institute, Cary, NC).

\section{Results}

\section{Patient Characteristics}

The final $\mathrm{CH}$ cohort comprised 6,562 adult patients (aged $>18$ years) with $2 \mathrm{CH}$ diagnoses and at least 2 years of continuous enrollment (Figure 1). CH patients were mainly male (59.3\%), between 35 and 64 years of age (73.8\%), and resided in the North Central or South regions of the United States (61.6\%; Table 1). Approximately $91 \%$ of $\mathrm{CH}$ patients were covered by commercial-only insurance. Most $\mathrm{CH}$ patients were initially diagnosed by their primary care physician (42.0\%), followed by a neurologist (18.0\%) and an inpatient hospital physician (12.6\%), with the remaining $27.3 \%$ diagnosed by an "other" or unspecified provider. Differences in demographic and baseline medical characteristics were adjusted by PSBB analyses.

\section{HCRU and Total Costs: All Cause}

Resource utilization comparisons between $\mathrm{CH}$ patients and controls during post-index are presented in Table 2. Although nearly all $\mathrm{CH}$ patients and controls had $\geq 1$ outpatient visit annually ( $100 \%$ vs. $96.4 \%$; $P<0.001), \mathrm{CH}$ patients had a 2 - to 3 -fold greater number of mean annual claims for outpatient visits (26.5 vs. 12.4 visits; $P<0.001)$. Likewise, greater portions of $\mathrm{CH}$ patients reported $\geq 1 \mathrm{ED}$ visit (36.9\% vs. $16.2 \%)$ and hospital visit $(14.8 \%$ vs. $6.1 \%)$ versus controls (each $P<0.001)$. The mean numbers of annual ED visits (0.98 vs. 0.25 visits) and annual hospital visits ( 0.22 vs. 0.08 visits) were more than 2 -fold higher for $\mathrm{CH}$ patients versus controls (each $\mathrm{P}<0.001$ ). More than 13 times as many $\mathrm{CH}$ patients as controls reported $\geq 1$ neurology visit $(45.2 \%$ vs. $3.3 \% ; P<0.001)$. The mean number of annual 


\begin{tabular}{|c|c|c|c|}
\hline Characteristics & $\begin{array}{c}\text { Cluster Headache } \\
(\mathrm{n}=6,562)\end{array}$ & $\begin{array}{c}\text { Control } \\
(\mathrm{n}=143,761)\end{array}$ & $P$ Value \\
\hline \multicolumn{4}{|l|}{ Gender, n (\%) } \\
\hline Male & $3,890 \quad(59.3)$ & $80,830 \quad(56.2)$ & $<0.0001$ \\
\hline Female & $2,672 \quad(40.7)$ & $62,931 \quad(43.8)$ & \\
\hline \multicolumn{4}{|l|}{ Age at index, years } \\
\hline Mean \pm SD & $47.1 \pm 13.3$ & $47.9(13.4)$ & $<0.0001$ \\
\hline Median & 48 & 48 & \\
\hline \multicolumn{4}{|l|}{ Age group, n (\%) } \\
\hline $18-24$ & $331 \quad(5.0)$ & $6,232 \quad(4.3)$ & $<0.0001$ \\
\hline $25-34$ & $876 \quad(13.3)$ & $18,069 \quad(12.6)$ & \\
\hline $35-44$ & $1,525 \quad(23.2)$ & $32,271 \quad(22.4)$ & \\
\hline $45-54$ & $1,906 \quad(29.0)$ & $41,802 \quad(29.1)$ & \\
\hline $55-64$ & $1,415 \quad(21.6)$ & $32,187 \quad(22.4)$ & \\
\hline $65+$ & $509 \quad(7.8)$ & $13,200 \quad(9.2)$ & \\
\hline \multicolumn{4}{|l|}{ Primary insurer, n (\%) } \\
\hline Commercial & $5,989 \quad(91.3)$ & $128,986 \quad(89.7)$ & $<0.0001$ \\
\hline Supplemental Medicare & $573 \quad(8.7)$ & $14,775 \quad(10.3)$ & \\
\hline \multicolumn{4}{|c|}{ Charlson Comorbidity Index } \\
\hline Mean \pm SD & $0.66 \pm 1.33$ & $0.49 \pm 1.16^{\mathrm{a}}$ & $<0.0001$ \\
\hline Median & 0 & 0 & \\
\hline \multicolumn{4}{|l|}{ Region, n (\%) } \\
\hline North Central & $1,658 \quad(25.3)$ & $37,025 \quad(25.8)$ & 0.1390 \\
\hline Northeast & $993 \quad(15.1)$ & $22,735 \quad(15.8)$ & \\
\hline South & $2,382 \quad(36.3)$ & $52,273 \quad(36.4)$ & \\
\hline West & $1,386 \quad(21.1)$ & $28,651 \quad(19.9)$ & \\
\hline Unknown & $143 \quad(2.2)$ & $3,077 \quad(2.1)$ & \\
\hline \multicolumn{4}{|c|}{ Provider who assigned cluster headache diagnosis ${ }^{b}$} \\
\hline Inpatient HCP & $830 \quad(12.6)$ & - & NA \\
\hline ED HCP & $41 \quad(0.6)$ & - & \\
\hline Primary care physician & $2,756 \quad(42.0)$ & - & \\
\hline Neurologist & $1,180 \quad(18.0)$ & - & \\
\hline Unspecific/Other & $1,755 \quad(26.7)$ & - & \\
\hline \multicolumn{4}{|c|}{ Pre-index total costs, USD } \\
\hline Mean \pm SD & $12,359 \pm 27,251$ & $6,552 \pm 21,088$ & $<0.0001$ \\
\hline Median & 4,714 & 1,878 & \\
\hline \multicolumn{4}{|c|}{$\begin{array}{l}\text { aFor controls, } n=139,322 \text {. } \\
\text { bProvider type assigned based on initial cluster headache diagnosis. } \\
\text { cAll costs adjusted to } 2014 \text { USD using the medical care services component of the } \\
\text { Consumer Price Index. } \\
E D=\text { emergency department; HCP = health care provider; NA= not available; } \\
S D=\text { standard deviation; USD =U.S. dollars. }\end{array}$} \\
\hline
\end{tabular}

neurology visits was also greater for $\mathrm{CH}$ patients versus controls (1.6 vs. 0.1 visits, $P<0.001$ ). Among $\mathrm{CH}$ patients, $76.5 \%$ had $\geq 1$ radiology visit versus $52.1 \%$ of controls $(P<0.001)$. The mean numbers of annual radiology and laboratory visits were 2-fold higher in $\mathrm{CH}$ patients versus controls (3.6 vs. 1.7, $\mathrm{P}<0.001$ and 3.8 vs. $2.1, P<0.001$, respectively).

Annual mean total direct costs for all-cause adjudicated claims were more than double during post-index $(\$ 16,530)$ for $\mathrm{CH}$ patients versus controls $(\$ 7,197)$, a net incremental cost of
$\$ 9,333(P<0.0001$; Table 2$)$. The principal driver of the cost difference was outpatient visits (mean $\$ 8,052$ for $\mathrm{CH}$ patients vs. $\$ 3,783$ for controls; $P<0.001$ ), followed by inpatient hospital visits (mean $\$ 4,467$ for $\mathrm{CH}$ patients vs. $\$ 1,720$ for controls; $P<0.001$ ). ED visits were associated with nearly 4 -fold greater annual mean costs, from $\$ 1,502$ for $\mathrm{CH}$ patients to $\$ 376$ for controls $(P<0.001)$. In addition, annual mean costs were approximately 15-fold higher in $\mathrm{CH}$ patients versus controls for neurology visits ( $\$ 341$ vs. $\$ 23 ; P<0.001$ ). CH patients spent nearly 3-fold more on radiology visits than controls $(\$ 1,418$ vs. \$483). Among $\mathrm{CH}$ patients with oxygen claims (20\%; $\mathrm{n}=1,318$ ), an average of $\$ 870 /$ patient was reported related to oxygen equipment and services during the 12-month postindex period. Finally, annual mean costs attributable to pharmacy claims also were significantly (2-fold) greater among $\mathrm{CH}$ patients versus controls ( $\$ 2,509$ vs. $\$ 1,319 ; P<0.001)$.

\section{HCRU and Total Costs: Headache and Cluster Headache}

Resource utilization and costs linked to claims with headache-related and $\mathrm{CH}$-specific diagnoses during post-index are summarized in Table 2. Utilization of headache-related/ $\mathrm{CH}$-specific outpatient, ED, and inpatient resources was reported for approximately 98\%/95\%, 20\%/12\%, and 9\%/6\% of $\mathrm{CH}$ patients, respectively. The annual mean numbers of outpatient, ED, and inpatient visits attributable to headacherelated/CH-specific diagnoses were 6.85/4.12, 0.41/0.18, and $0.10 / 0.07$ visits, respectively. Other mean annual numbers of visits attributed to headache-related/CH-specific diagnoses in descending order were 1.26/0.71 for neurology visits, 0.72/0.27 for radiology visits, and 0.25/0.09 for laboratory procedures.

Mean annual total direct costs for headache-related/ $\mathrm{CH}$-specific claims, excluding pharmacy costs, were $\$ 3,043 / \$ 1,564$ during post-index, which were largely attributable to outpatient costs $(\$ 1,571 / \$ 808)$, followed by inpatient (\$879/\$498) and ED visits (\$592/\$259). Other mean annual direct costs for headache-related/CH-specific diagnoses included $\$ 447 / \$ 175$ for radiology and $\$ 239 / \$ 116$ for neurology consultations.

\section{Common Reasons for ED and Inpatient Hospital Admissions}

The top 10 reasons for ED and inpatient hospital admissions for $\mathrm{CH}$ patients are listed in Table 3, along with the ranking of each reason relative to controls. Reasons for ED visits that occurred more often among $\mathrm{CH}$ patients included the following: gastric ulcer with hemorrhage (ranked 1 [7.1\%] vs. 120 [0.18\%]), subarachnoid hemorrhage (ranked 3 [3.6\%] vs. 143 [0.15\%]), migraine with aura (ranked 5 [2.5\%] vs. comparison unavailable for controls), headache symptoms (ranked 8 [2.0\%] vs. $164[0.13 \%]$ ), and syncope and collapse (ranked 6 [2.1\%] vs. 13 [1.1\%]). Reasons for hospital admissions that occurred more often among $\mathrm{CH}$ patients included the following: cerebral 
TABLE 2 Health Care Resource Utilization and Direct Costs During the 12 Months Post-Index: All-Cause, Headache-Related, and Cluster Headache-Specific Claims

\begin{tabular}{|c|c|c|c|c|c|c|}
\hline \multicolumn{7}{|c|}{ All-Cause Analysis } \\
\hline & $\begin{array}{c}\text { Cluster Headache } \\
(\mathrm{n}=6,562)\end{array}$ & $\begin{array}{c}\text { Control } \\
(n=143,761)\end{array}$ & $\begin{array}{l}\text { Adjusted } \\
P \text { Value }\end{array}$ & $\begin{array}{c}\text { Adjusted } \\
\text { 95\% CI for } \\
\text { the Difference }\end{array}$ & $\begin{array}{c}\text { Headache-Related } \\
(\mathrm{n}=6,562)\end{array}$ & $\begin{array}{l}\text { Cluster } \\
\text { Headache- } \\
\text { Specific } \\
(\mathrm{n}=6,562)\end{array}$ \\
\hline \multicolumn{7}{|l|}{ Health care resource utilization and total costs ${ }^{\mathrm{a}}$} \\
\hline Total costs, mean $\pm \mathrm{SD}, \mathrm{USD}$ & $16,530 \pm 40,068$ & $7,197 \pm 25,147$ & $<0.0001$ & $5,974-7,523$ & $3,043 \pm 7,423^{b}$ & $1,564 \pm 5,015^{b}$ \\
\hline \multicolumn{7}{|l|}{ Outpatient } \\
\hline Patients with any visit, $\mathrm{n}(\%)$ & $6,560(100.0)$ & $138,575 \quad(96.4)$ & $<0.001$ & $3.49-3.69$ & $6,453 \quad(98.3)$ & $6,232 \quad(95.0)$ \\
\hline Mean \pm SD number of visits & $26.49 \pm 26.46$ & $12.40 \pm 16.28$ & $<0.001$ & $11.52-12.63$ & $6.85 \pm 7.63$ & $4.12 \pm 4.59$ \\
\hline Mean \pm SD, USD & $8,052 \pm 16,470$ & $3,783 \pm 14,393$ & $<0.001$ & $2,980-3,687$ & $1,571 \pm 2,925$ & $808 \pm 1905$ \\
\hline \multicolumn{7}{|l|}{ Inpatient } \\
\hline Patients with any admission, $\mathrm{n}(\%)$ & $972 \quad(14.8)$ & $8,817 \quad(6.1)$ & $<0.001$ & $5.93-7.70$ & $558 \quad(8.5)$ & $(6.2)$ \\
\hline Mean \pm SD number of admissions & $0.22 \pm 0.69$ & $0.08 \pm 0.36$ & $<0.001$ & $0.09-0.11$ & $0.10 \pm 0.40$ & $0.07 \pm 0.27$ \\
\hline Mean \pm SD, USD & $4,467 \pm 28,121$ & $1,720 \pm 16,331$ & $<0.001$ & $1,276-2,357$ & $879 \pm 5,424$ & $498 \pm 4,371$ \\
\hline \multicolumn{7}{|l|}{ ED } \\
\hline Patients with any ED visits, $\mathrm{n}(\%)$ & $2,418 \quad(36.9)$ & $23,224 \quad(16.2)$ & $<0.001$ & $16.37-18.89$ & $1,320 \quad(20.1)$ & $791 \quad(12.1)$ \\
\hline Mean \pm SD number of visits & $0.98 \pm 2.76$ & $0.25 \pm 0.79$ & $<0.001$ & $0.49-0.60$ & $0.41 \pm 1.54$ & $0.18 \pm 0.57$ \\
\hline Mean \pm SD, USD & $1,502 \pm 6,322$ & $376 \pm 1,892$ & $<0.001$ & $681-914$ & $592 \pm 2,756$ & $259 \pm 1,340$ \\
\hline \multicolumn{7}{|l|}{ Pharmacy } \\
\hline Patients with any pharmacy claims, n (\%) & $5,128 \quad(78.2)$ & $105,022 \quad(73.1)$ & $<0.001$ & $2.74-6.71$ & $\mathrm{NA}^{\mathrm{c}}$ & $\mathrm{NA}^{\mathrm{c}}$ \\
\hline Mean \pm SD, USD & $2,509 \pm 6,557$ & $1,319 \pm 5,105$ & $<0.001$ & $662-962$ & NA & NA \\
\hline \multicolumn{7}{|l|}{ Neurology } \\
\hline Patients with any neurology visits, $\mathrm{n}(\%)$ & $2,963 \quad(45.2)$ & (3.3) & $<0.001$ & $38.85-41.11$ & $2,718 \quad(41.4)$ & $1,885 \quad(28.7)$ \\
\hline Mean \pm SD number of visits & $1.57 \pm 2.78$ & $0.08 \pm 0.62$ & $<0.001$ & $1.28-1.41$ & $1.26 \pm 2.26$ & $0.71 \pm 1.43$ \\
\hline Mean \pm SD, USD & $341 \pm 1,078$ & $23 \pm 445$ & $<0.001$ & $252-297$ & $239 \pm 613$ & $116 \pm 275$ \\
\hline \multicolumn{7}{|l|}{ Radiology } \\
\hline Patients with any service, $\mathrm{n}(\%)$ & $5,022 \quad(76.5)$ & $74,857 \quad(52.1)$ & $<0.001$ & $22.84-25.22$ & $2,559 \quad(39.0)$ & $1,286 \quad(19.6)$ \\
\hline Mean \pm SD number of visits & $3.55 \pm 5.23$ & $1.66 \pm 3.14$ & $<0.001$ & $1.50-1.74$ & $0.72 \pm 1.39$ & $0.27 \pm 0.77$ \\
\hline Mean \pm SD, USD & $1,418 \pm 3,236$ & $483 \pm 2,381^{\mathrm{d}}$ & $<0.001$ & $698-853$ & $447 \pm 1,088$ & $175 \pm 660$ \\
\hline \multicolumn{7}{|l|}{ Laboratory } \\
\hline Patients with any service, n (\%) & $544 \quad(8.3)$ & 8,376 & $<0.001$ & $1.49-3.48$ & $(0.7)$ & $(0.3)$ \\
\hline Mean \pm SD number of visits & $3.75 \pm 25.83$ & $2.08 \pm 14.57$ & $<0.001$ & $0.69-1.80$ & $0.25 \pm 3.49$ & $0.09 \pm 2.07$ \\
\hline Mean \pm SD, USD & NA & NA & NA & NA & NA & NA \\
\hline \multicolumn{7}{|c|}{$\begin{array}{l}\text { aAll costs adjusted to } 2014 \text { USD using the medical care services component of the Consumer Price Index. } \\
\text { bTotal cost of claims associated with headache-related and cluster headache-specific diagnosis included inpatient, outpatient, and ED cost. } \\
\text { cPharmacy claims associated with headache-related or cluster headache-specific diagnosis could not be determined as ICD-9-CM codes were not captured in pharmacy claims. } \\
{ }^{d} \text { For controls, } n=143,734 \text {. } \\
C I=\text { confidence interval; } E D=\text { emergency department; ICD-9-CM=International Classification of Diseases, Ninth Revision, Clinical Modification; NA=not available; } \\
\text { SD= standard deviation; USD =U.S. dollars. }\end{array}$} \\
\hline
\end{tabular}

artery occlusion, unspecified with cerebral infarction (ranked 3 [1.9\%] vs. 13 [1.0\%]), headache symptoms (ranked 7 [1.6\%] vs. $334[0.06 \%]$ ), and syncope and collapse (ranked 8 [1.5\%] vs. 27 [0.6\%]). Moreover, when the numbers of patients with each principal diagnosis code captured in the ED were compared (data not shown), $\mathrm{CH}$ patients were nearly 31 times more likely to visit the ED due to depressive disorder not elsewhere classified (ICD-9-CM code 311.xx), 17 times more likely to visit the ED due to a convulsion (ICD-9-CM code 780.39), and 7 times more likely to visit the ED due to major depressive affective disorder (ICD-9-CM code 296.33).

\section{Discussion}

Burden-of-illness information is scant for patients with $\mathrm{CH}$ who reside in the United States. Accordingly, information gathered from the large, geographically diverse U.S. Truven Health Analytics MarketScan Research Databases described herein represents the first study to assess direct HCRU and associated costs among 6,562 adult patients with at least $2 \mathrm{CH}$ diagnoses. This study provides comprehensive information on annual HCRU and cost burden of $\mathrm{CH}$ as compared with a control population. Regardless of cause, nearly all $\mathrm{CH}$ patients and controls had $\geq 1$ outpatient visit during 1-year post-index, although $\mathrm{CH}$ patients had an average of significantly more 
TABLE 3 Top 10 Reasons for ED Visits and Inpatient Hospital Admissions for Cluster Headache Patients Based on Principal Diagnosis Code

\begin{tabular}{|c|c|c|c|}
\hline ICD-9-CM Code & Description & $\%$ (vs. Controls) & Ranking (vs. Controls) \\
\hline \multicolumn{4}{|l|}{ ED visits } \\
\hline 531.40 & $\begin{array}{l}\text { Chronic or unspecified gastric ulcer with hemorrhage, without mention of } \\
\text { obstruction }\end{array}$ & 7.1 vs. 0.18 & 1 vs. 120 \\
\hline 786.59 & Chest pain NEC & 4.0 vs. 2.3 & 2 vs. 5 \\
\hline 430 & Subarachnoid hemorrhage & 3.6 vs. 0.15 & 3 vs. 143 \\
\hline 434.91 & Cerebral artery occlusion, unspecified with cerebral infarction & 3.1 vs. 1.6 & 4 vs. 7 \\
\hline 346.00 & $\begin{array}{l}\text { Migraine with aura, without mention of intractable migraine without mention of } \\
\text { status migrainosus }\end{array}$ & 2.5 vs. 0.0 & 5 vs. NA \\
\hline 780.2 & Syncope and collapse & 2.1 vs. 1.1 & 6 vs. 13 \\
\hline 562.11 & Diverticulitis of colon (without mention of hemorrhage) & 2.1 vs. 1.3 & 7 vs. 10 \\
\hline 784.0 & Headache & 2.0 vs. 0.13 & 8 vs. 164 \\
\hline 414.01 & Coronary atherosclerosis of native coronary artery & 1.9 vs. 2.7 & 9 vs. 4 \\
\hline 410.71 & Subendocardial infarction, initial episode of care & 1.9 vs. 3.0 & 10 vs. 3 \\
\hline \multicolumn{4}{|c|}{ Inpatient admissions } \\
\hline 786.59 & Chest pain NEC & 2.1 vs. 1.4 & 1 vs. 10 \\
\hline V57.89 & Care involving other specified rehabilitation procedure & 2.1 vs. 1.5 & 2 vs. 6 \\
\hline 434.91 & Cerebral artery occlusion, unspecified with cerebral infarction & 1.9 vs. 1.0 & 3 vs. 13 \\
\hline 486 & Pneumonia, organism unspecified & 1.7 vs. 2.0 & 4 vs. 3 \\
\hline 414.01 & Coronary atherosclerosis of native coronary artery & 1.7 vs. 2.7 & 5 vs. 2 \\
\hline 715.36 & Osteoarthrosis, localized, not specified whether primary or secondary, lower leg & 1.7 vs. 2.9 & 6 vs. 1 \\
\hline 784.0 & Headache & 1.6 vs. 0.06 & 7 vs. 334 \\
\hline 780.2 & Syncope and collapse & 1.5 vs. 0.6 & 8 vs. 27 \\
\hline 562.11 & Diverticulitis of colon (without mention of hemorrhage) & 1.3 vs. 1.0 & 9 vs. 12 \\
\hline 715.35 & $\begin{array}{l}\text { Osteoarthrosis, localized, not specified whether primary or secondary, pelvic region } \\
\text { and thigh }\end{array}$ & 1.2 vs. 1.4 & 10 vs. 9 \\
\hline
\end{tabular}

visits (26 vs. 12 for controls). Annual rates for at least 1 ED visit (37\%) or inpatient visit (15\%) were also significantly higher in $\mathrm{CH}$ patients than controls; for $\mathrm{CH}$ patients, this equated to an average of nearly 1 ED visit per patient per year and 1 hospital admission per patient every 5 years. As expected, $\mathrm{CH}$ patients were more than 13 -fold more likely during the year to have a neurology visit versus controls. Finally, radiology and laboratory visits were significantly 2.0-fold greater in $\mathrm{CH}$ patients versus controls. This high rate of HCRU supports the finding that the total annual all-cause direct medical and pharmacy costs were 130\% higher in $\mathrm{CH}$ patients versus controls, representing a net incremental annual medical and pharmacy cost of $\$ 9,333$ per $\mathrm{CH}$ patient. Based on our cost findings, the 2014 U.S. population of approximately $320,000,000,{ }^{14}$ and the estimated 1-year prevalence of 53 per 100,000 (CI 26, 95) for U.S. patients diagnosed with $\mathrm{CH},{ }^{3}$ more than $\$ 2.8$ billion/year total direct cost will be spent to care for $\mathrm{CH}$ patients.

It is possible that other headache-related diagnoses were inappropriately assigned to $\mathrm{CH}$-specific service. Thus, we conducted 2 separate analyses based on headache-related diagnoses and $\mathrm{CH}$-specific diagnoses. Headache-related and $\mathrm{CH}$-specific claims accounted for $22 \%$ and $11 \%$ of all-cause direct total costs (excluding pharmacy), respectively. For both subgroups, more than half the costs were attributable to outpatient care, followed by inpatient costs and ED costs. Neurology consultation due to headache-related diagnoses accounted for $70 \%$, and $\mathrm{CH}$-specific diagnoses accounted for one third of allcause neurology costs. Radiology costs due to headache-related and $\mathrm{CH}$-specific diagnoses, including medical imaging such as magnetic resonance imaging and positron emission tomography, accounted for $\sim 32 \%$ and $\sim 12 \%$ of total all-cause radiology costs, respectively. Pharmacy costs due to headache-related and $\mathrm{CH}$-specific claims were not analyzed because diagnosis associated with each medication was not available. Overall, our analysis found relatively low annual $\mathrm{CH}$-specific costs and HCRU, even after we accounted for headache-related diagnosis. This suggests that many $\mathrm{CH}$ patients had comorbid conditions that drove these outcomes.

The mean direct cost of HCRU of $\mathrm{CH}$ in our study $(\$ 16,530 /$ year) compares similarly with a previous cost estimate from a German survey study ( $n=179$ ) of $€ 4,737$ over a 6-month period (\$14,214/year fiscal year 2014). ${ }^{7}$ However, the largest health care expense for German patients came from acute and prophylactic medications, followed by inpatient and outpatient services. ${ }^{7}$ In comparison, nearly half of the total cost in our study came from outpatient visits, followed by inpatient 
visits and pharmacy costs. Yet, Gaul et al. (2011) only included patients diagnosed by experienced neurologists, and patients were treated at a headache center. ${ }^{7}$ In contrast, our study included patients diagnosed primarily by primary care providers (42\%) and less often by neurologists (18\%). Furthermore, our patients were potentially "newly" diagnosed with $\mathrm{CH}$ or were remitted after a long period of remission (i.e., no $\mathrm{CH}$ claims in 12 months before the index date), in contrast with patients with long duration of the disease (i.e., > 12 years) in the Gaul et al. study.

In our study, all-cause costs, rather than $\mathrm{CH}$-specific costs, drove the economic burden. That is, $\mathrm{CH}$-specific ED and inpatient visit rates were one third to one half of the total all-cause visit rates. The higher usage of these services in all-cause $\mathrm{CH}$ patients is likely due to higher frequency of comorbidities. It is not unexpected that use of $\mathrm{ED}$ and inpatient services due to $\mathrm{CH}$ were not major drivers of $\mathrm{CH}$-specific costs, likely based on the relatively short time interval of extreme intense pain associated with $\mathrm{CH}$ attacks (i.e., 15-180 minutes). ${ }^{1}$ However, there were many diagnoses that occurred more often among $\mathrm{CH}$ patients for an ED visit or inpatient admission (based on principal ICD9-CM diagnosis codes) versus controls. Migraine with aura and headache symptoms (ICD-9-CM 346.0 and 784.0, respectively) are expected reasons for ED visits among $\mathrm{CH}$ patients, whereas gastric ulcer with hemorrhage and subarachnoid hemorrhage (the 2 leading reasons for ED visits) were unexpected. Similarly, headache symptoms were a more frequent but expected reason for hospital admission among $\mathrm{CH}$ patients, whereas cerebral artery occlusion with cerebral infarction was an unusual cause. It is possible that the GI bleeding events may be related to NSAID or other medication use ${ }^{15}$ and that subarachnoid hemorrhage and cerebral artery occlusion/infarction were related to underlying pathophysiology (e.g., diverse cranial structural abnormalities). ${ }^{16}$ Whether these reasons for ED visits and inpatient admissions are truly linked to $\mathrm{CH}$ is complicated and deserves further investigation.

It is important to recognize that neuroimaging is expensive and has very low yield in headache patients. ${ }^{17}$ In our study, significantly more $\mathrm{CH}$ patients used radiology services, including neuroimaging, compared with controls. The radiology services used by $\mathrm{CH}$ patients were also more expensive than services used by controls (\$854/visit vs. $\$ 136 /$ visit). As a result, $\mathrm{CH}$ patients spent approximately $\$ 1,418 /$ year on radiology services-far more than costs directly attributed to neurology visits ( $\$ 341 /$ year). However, given the intensity of $\mathrm{CH}$ pain, neuroimaging is warranted to rule out secondary causes for headache such as cerebral tumors. ${ }^{17}$ Although the reason for overuse of radiology resources is unknown, there may be many clinical and nonclinical reasons such as a lack of physician awareness or familiarity with $\mathrm{CH}$ symptoms, or the fear of missing something life threatening by either the physician or patient who may be highly motivated to find an answer to such excruciating pain. Even though $\mathrm{CH}$ has clear clinical presentations (e.g., unilateral high-intensity pain lasting less than 180 minutes, eyelid edema, myosis), a decade-old study suggested that many patients report that diagnosis is delayed for years. ${ }^{18}$ For example, many $\mathrm{CH}$ patients with $\mathrm{ED}$ visits and inpatient hospital admissions (Table 3) were assigned an unspecific migraine diagnosis (ICD-9-CM code 346.00) and headache symptoms (ICD-9-CM code 784.0). A validated screening tool designed to identify patients with $\mathrm{CH}$ in various clinical settings is likely to improve diagnosis and management of $\mathrm{CH}$ patients.

High-flow oxygen is considered one of the most effective, safe, and well-tolerated abortive/acute treatments for $\mathrm{CH}^{5}{ }^{5}$ Based on results of a 10-year-old study, nearly one third of $\mathrm{CH}$ patients have not tried this approach despite the fact that 64\% of surveyed patients were offered coverage. ${ }^{9}$ A more recent study reported that most private insurance companies now reimburse the cost of oxygen used to treat acute episodes in $\mathrm{CH}$ patients. ${ }^{19}$ Yet our study found that only $20 \%$ of patients were prescribed oxygen. The underuse of oxygen may be due to physicians' lack of awareness of the usefulness of oxygen, difficulty in finding a source for oxygen, complicated equipment operation, and perceived lack of insurance coverage and high cost. It was unclear what commercial insurance coverage was available for oxygen use during our study period; it is possible that oxygen use was underestimated. Although mean direct costs associated with oxygen use appeared low (\$175/patient) in the 1-year post-index of our study, considering that only $20 \%$ of $\mathrm{CH}$ patients received oxygen treatment, patients with oxygen use claims spent approximately $\$ 871$ /year on high-flow oxygen for abortive/acute treatment. This cost figure is consistent with 2 other studies that estimated episodic $\mathrm{CH}$ patients spent less than $\$ 1,000 /$ year on oxygen treatment. ${ }^{9,19}$ Further research is needed to gain insight into the underutilization of oxygen treatment.

Our previous study showed that $25 \%$ of $\mathrm{CH}$ patients reported greater than 12 different prescription drug claims with a significantly larger variety of medications than controls. ${ }^{10}$ We also noticed that many $\mathrm{CH}$ patients received treatments inconsistent with treatment guidelines. ${ }^{5} \mathrm{CH}$ patients who had claims for recognized treatments without opioids had the lowest utilization of ED and inpatient hospital visits, suggesting effective treatment could reduce direct cost. Management of $\mathrm{CH}$ patients warrants special medical and further supportive care to diminish the burden of disease, as well as direct and indirect treatment costs.

\section{Limitations}

This study has some limitations to consider. As with all claims analyses, diagnostic accuracy is unknown. This is especially true where the rarity or unfamiliarity in general practice with $\mathrm{CH}$ may result in misuse or lack of use of proper codes. Accordingly, two thirds of patients only had 1 diagnostic claim 
for $\mathrm{CH}$ and were excluded from this analysis, which may indicate that $\mathrm{CH}$ codes are being used as a screen-out for other conditions or that some physicians are inconsistently using the codes. Furthermore, misdiagnosed patients with migraine may have been included in the $\mathrm{CH}$ cohort. A recent study of the validity of $\mathrm{CH}$ diagnoses in an electronic health record data repository showed a relatively modest positive predictive value when 1 ICD-9-CM code was used relative to a headache expert's clinical impression; however, our study required 2 codes to reduce classification bias. ${ }^{20}$ Also, the ICD-9-CM diagnosis codes for $\mathrm{CH}$ were not available before 2008, which disallowed $\mathrm{CH}$ patient inclusion before this date.

Finally, our study population may not be representative of $\mathrm{CH}$ patients because only those with employee-based health insurance or Medicare supplemental insurance were included. Characteristics of $\mathrm{CH}$ and its HCRU and cost patterns in the general population may be different from the population studied in this claims database.

\section{Conclusions}

This direct HCRU and cost study demonstrated that $\mathrm{CH}$ is extremely burdensome to the patient. Our cost findings suggest that from a payer perspective, $\mathrm{CH}$ patients incur significantly higher health care costs versus controls; however, these high costs were not exclusively headache-related. Future studies are needed to further explore the reasons and extent of $\mathrm{CH}$ on direct costs in the U.S. health care system.

\section{Authors}

CASEY K. CHOONG, MPH; JANET H. FORD, PhD; ALLEN W. NYHUIS, MS; REBECCA L. ROBINSON, MS; and SHEENA K. AURORA, MD, Eli Lilly and Company, Indianapolis, Indiana.

AUTHOR CORRESPONDENCE: Casey K. Choong, MPH, Eli Lilly and Company, Lilly Corporate Center, Indianapolis, IN 46285. Tel.: 317.276.9065; E-mail: choong@lilly.com.

\section{DISCLOSURES}

Eli Lilly and Company was the sole sponsor and funder for this study and was responsible for the study design, data collection, data analysis, interpretation of data, and decision to publish the findings. All authors are employees and minor stockholders of Eli Lilly and Company.

\section{ACKNOWLEDGMENTS}

Writing support was provided by Teresa Tartaglione, PharmD (Synchrogenix, a Certara Company, Wilmington, DE). The authors also thank Krista Schroeder of Eli Lilly and Company for additional analyses performed.

\section{REFERENCES}

1. Headache Classification Committee of the International Headache Society. The International Classification of Headache Disorders, 3rd edition (beta version). Cephalalgia. 2013;33(9):629-808

2. Buture A, Gooriah R, Nimeri R, Ahmed F. Current understanding on pain mechanism in migraine and cluster headache. Anesth Pain Med. 2016;6(3):e35190.

3. Fischera M, Marziniak M, Gralow I, Evers S. The incidence and prevalence of cluster headache: a meta-analysis of population-based studies. Cephalalgia. 2008;28(6):614-18.

4. Hughes C. ICD-9 codes: time for the annual update. Available at: http:// www.aafp.org/fpm/2008/0900/pa3.pdf. Accessed May 22, 2018.

5. Robbins MS, Starling AJ, Pringsheim TM, Becker WJ, Schwedt TJ. Treatment of cluster headache: the American Headache Society evidencebased guidelines. Headache. 2016;56(7):1093-106.

6. Jurgens TP, Gaul C, Lindwurm A, et al. Impairment in episodic and chronic cluster headache. Cephalalgia. 2011;31(6):671-82.

7. Gaul C, Finken J, Biermann J, et al. Treatment costs and indirect costs of cluster headache: a health economics analysis. Cephalalgia. 2011;31(16):1664-72.

8. Jensen RM, Lyngberg A, Jensen RH. Burden of cluster headache. Cephalalgia. 2007:27(6):535-41.

9. Rozen TD, Fishman RS. Inhaled oxygen and cluster headache sufferers in the United States: use, efficacy and economics: results from the United States Cluster Headache Survey. Headache. 2011;51(2):191-200.

10. Choong CK, Ford JH, Nyhuis AW, et al. Clinical characteristics and treatment patterns among patients diagnosed with cluster headache in U.S. healthcare claims data. Headache. 2017;57(9):1359-74.

11. Clemans-Cope L, Holahan J, Garfield R. Medicaid spending growth compared to other payers: a look at the evidence. Kaiser Family Foundation. Issue Brief. April 2016. Available at: http://www.kff.org/report-section/ medicaid-spending-growth-compared-to-other-payers-issue-brief. Accessed May 22, 2018

12. Foster SA, Zhu B, Guo J, et al. Patient characteristics, health care resource utilization, and costs associated with treatment-regimen failure with biologics in the treatment of psoriasis. J Manag Care Spec Pharm. 2016;22(4):396-405. Available at: https://www.jmcp.org/doi/10.18553/ jmcp.2016.22.4.396.

13. Quan H, Sundararajan V, Halfon P, et al. Coding algorithms for defining comorbidities in ICD-9-CM and ICD-10 administrative data. Med Care 2005;43(11):1130-39.

14. U.S. Census Bureau. U.S. and world population clock. Available at: https://www.census.gov/popclock/. Accessed May 22, 2018.

15. Pardutz A, Schoenen J. NSAIDs in the acute treatment of migraine: a review of clinical and experimental data. Pharmaceuticals (Basel). 2010;3(6):1966-87.

16. Valença MM, Andrade-Valença LP, Martins C, et al. Cluster headache and intracranial aneurysm. J Headache Pain. 2007;8(5):277-82.

17. Holle D, Obermann M. The role of neuroimaging in the diagnosis of headache disorders. Ther Adv Neurol Disord. 2013;6(6):369-74.

18. Rozen TD, Fishman RS. Cluster headache in the United States of America: demographics, clinical characteristics, triggers, suicidality, and personal burden. Headache. 2012;52(1):99-113.

19. O'Brien M, Ford JH, Aurora S, et al. Economics of inhaled oxygen use as an acute therapy for cluster headache in the United States of America. Headache. 2017;57(9):1416-27.

20. Rizzoli P, Loder E, Joshi S. Validity of cluster headache diagnoses in an electronic health record data repository. Headache. 2016;56(7):1132-36. 